\title{
Shaping the Transition
}

\section{Dear Reader,}

Legislation will dramatically change the automotive landscape in the medium and long term, with increasing requirements concerning exhaust aftertreatment, the phasing out of the reduced mineral oil tax rate by the end of 2018 and above all due to progress in fully electric or electrified vehicles.

The Shell Passenger Car Scenarios predict that the fleet of vehicles with an electric propulsion system will grow to a total of 10.1 million by 2040 , while the number of petrol- or diesel-powered vehicles will fall to 30.7 million in the same period. McKinsey's report even includes one scenario predicting that only around $5 \%$ of vehicles will have an internal combustion engine in 2050 . So does that mean that everything speaks in favour of electric powertrains? Not really, because added to the 31 million internal combustion powertrains of the Shell study are a further 5.5 million plug-in hybrids, while McKinsey forecasts a share of $35 \%$ for PHEVs. Internal combustion powertrains will therefore significantly determine our mobility even in three decades' time. Hydrogen fuel cell powertrains are at best still a distant vision, even though some analysts might be more optimistic. What is clear is that emissions of below $90 \mathrm{~g} \mathrm{CO}_{2} / \mathrm{km}$ are hardly possible without electrification or alternative fuels.

This means that, when it comes to the powertrain of the future, the fuel will be increasingly relevant. Even CNG, which is already on the market, is only a niche product in many countries - it makes up a mere $0.41 \%$ of the fuel mix throughout Europe, as reported in ATZ 2/2015. To make matters worse, the clear benefit of CNG in a monovalent configuration can hardly be exploited, as CNG powertrains are generally designed as bivalent systems for cost reasons. Wouldn't it therefore make more sense to use LNG?
In addition to the development of alternative fuels from fossil energy sources or biomass, such as methanol, DME, OME, ethanol or PME, there is also the important question of whether power-to-gas can be the best solution. The environmental performance of CNG with and without additives or bioethanol speaks for itself, although the environmental impact of fuels produced by power-toliquid technology using the same raw materials is not worse. These fuels have the further advantage that they can be globally distributed faster, more cheaply and more sustainably.

Fundamental decisions need to be taken to ensure that this intermediate step on the path towards electric mobility is successful, as a large number of different fuels would not be cost-effective for the industry and would hardly be accepted by consumers.

Best regards,

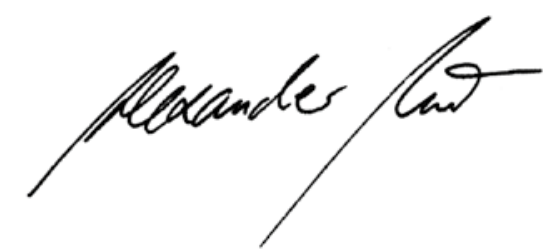

Dr. Alexander Heintzel, Editor in Chief Wiesbaden, 8 January 2015

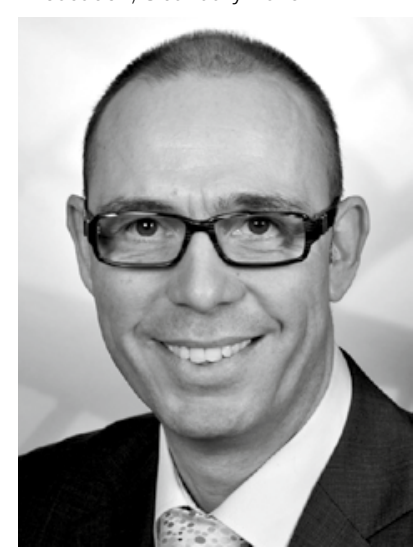

